\title{
Blood transfusion and hemostatic agents used during radical cystectomy
}

\author{
Nahid Punjani; Luke T. Lavallée, MD; Franco Momoli, PhD,; Dean Fergusson, PhD, MHA; Kelsey Witiuk, MSc; \\ Ranjeeta Mallick, PhD; ${ }^{\xi}$ Christopher Morash, MD, FRCSC; ; llias Cagiannos, MD, FRCSC; ${ }^{\dagger}$ \\ Rodney H. Breau, MSc, MD, FRCSC ${ }^{\text {'s }}$
}

*University of Ottawa Medical School, University of Ottawa, Ottawa, ON; 'Division of Urology, Department of Surgery, The Ottawa Hospital, University of Ottawa, Ottawa, ON; ${ }^{\circledR 0}$ tttawa Hospital Research Institute, Ottawa, ON

Cite as: Can Urol Assoc J 2013;7(5-6):e275-80. http://dx.doi.org/10.5489/cuaj.1002 Published online May 13, 2013.

\section{Abstract}

Background: Radical cystectomy may result in significant blood loss necessitating transfusion. The purpose of this study was to determine what intra-operative techniques and hemostatic agents are currently used by uro-oncologists to prevent and control blood loss during radical cystectomy.

Methods: In August 2011, members of the Society of Urologic Oncology (SUO) were solicited to complete an online survey. Residents, fellows and non-urologists were excluded. Canadian members received a personal email invitation. Respondents were asked to provide demographic information and opinions regarding blood loss and transfusion. Participants were also asked to report techniques used to reduce blood loss.

Results: Of the 34 Canadian SUO members with registered email addresses, 27 (79\%) completed the survey and met inclusion criteria as staff urologists who perform radical cystectomy. In addition, 52 non-Canadian SUO members were included in the analysis. Among all SUO respondents, a high proportion $(73 ; 88 \%)$ reported using topical hemostatic agents during cystectomy. Thirty-six (46\%) surgeons reported occasionally using procedural techniques and $9(11 \%)$ using systemic hemostatic agents. Number of years since training was associated with decreased use of topical agents and increased use of procedural techniques $(p<0.01)$. Number of cystectomies per year was associated with decreased use of topical hemostatic agents $(p<0.01)$.

Interpretation: Based on a survey of practice, there is significant risk of blood loss requiring transfusion during radical cystectomy. Surgeons frequently use topical hemostatic agents and rarely use systemic drugs to prevent or control blood loss. Trials evaluating agents and techniques to reduce blood loss during radical cystectomy are needed.

\section{Introduction}

Radical cystectomy and urinary reconstruction is technically challenging and associated with perioperative blood loss necessitating transfusion. ${ }^{1,2}$ Recent reviews of the cystectomy literature report median intra-operative blood loss between $600 \mathrm{~mL}$ and $1700 \mathrm{~mL}$, with the incidence of at least one intra-operative blood transfusion between $9 \%$ to $67 \%$ of procedures. ${ }^{1,3-5}$ While blood transfusions are effective, they are expensive, can cause patient anxiety, and may result in infectious disease transmission, immunosuppression and hemolytic reactions. ${ }^{6,7}$ Furthermore, radical cystectomy patients who receive a transfusion are $>50 \%$ more likely to experience other postoperative complications (e.g., ileus, urinary tract infection, wound dehiscence, wound infection or pneumonia), and those who require more than 4 units of packed red blood cells have a $70 \%$ increase in absolute risk of complications. ${ }^{8}$

In addition to meticulous surgical technique, methods to reduce blood loss during radical cystectomy can be categorized into topical hemostatic agents, systemic hemostatic agents and procedural hemostatic techniques. ${ }^{6,7,9,10}$ The use of these agents and techniques is at the discretion of the operating surgeon and anesthesiologist. Despite the frequent need for blood transfusion and a number of management options, little information is available to describe how surgeons prevent blood loss during radical cystectomy. We hypothesized that many urologists do not use systemic agents during radical cystectomy, despite evidence of benefit and safety of these drugs during other surgical procedures. ${ }^{9}$ 
Punjani et al.

\section{Methods}

\section{Recruitment}

On August 1, 2011, Society of Urologic Oncology (SUO) members with listed e-mail addresses were invited to participate in the "Anti-hemorrhagic Use During Radical Cystectomy" online survey. Reminder emails were sent 1 and 3 weeks after the original invitation. English-speaking Canadian members were emailed personally by the corresponding author $(\mathrm{RHB})$ to request their participation. We provided a hyperlink to an online survey that was linked to a secure database. The survey was closed on September 15, 2011. Institutional ethics review board approval was obtained prior to participant solicitation.

\section{Survey}

The survey was composed of 5 sections: demographics, transfusion opinions, topical hemostatic agents, systemic hemostatic agents and procedural hemostatic techniques. Demographic questions included academic position, years in practice, geographic location of practice and area of fellowship training. Participants were asked to estimate the number of radical cystectomies they perform yearly, the proportion that require perioperative transfusion, and what hemoglobin concentrations (triggers) prompt them to transfuse.

Participants were asked the proportion of radical cystectomy patients in which they use topical agents, such as oxidized cellulose polymer (Surgicel; Ethicon Inc., Somerville, NJ), absorbable gelatin sponge (Gelfoam; Pfizer, New York, NY), gelatin and thrombin matrix (Floseal; Baxter Healthcare Corporation, Hayward, CA), and thrombin and fibrinogen (Tisseel; Baxter Healthcare Corporation, Hayward, CA); systemic agents, such as recombinant activated Factor VII (Novoseven; Novo Nordisk Inc., Princeton, NJ), aminocaproic acid (Amicar; Xanodyne Pharmaceuticals, Inc; Newport, KY), tranexamic acid (Cyklokapron; Pfizer, New York, NY), aprotinin (Trasylol; Bayer Corp, Leverkusen, Germany), and desmopressin (DDAVP; Ferring Pharmaceuticals Ltd.; West Drayton, United Kingdom); and non-pharmacological procedural techniques, such as autologous blood recovery (CellSaver; Haemonetics, US), autologous blood banking, and acute normovolemic hemodilution. ${ }^{6,7,9,10}$ For each systemic agent listed, participants were asked why they use (or do not use) the drug.

\section{Statistical methods}

Descriptive summary statistics were generated. Each antihemorrhagic category (topical, systemic and procedural) was grouped as a composite dichotomous variable (ever use vs. never use). Respondents who used a particular method on at least one occasion were compared to those who had never used the same method. Responses were consistent between Canadians and all SUO respondents; therefore, all were included in the analysis. Associations between responses and demographic characteristics were calculated as unadjusted risk ratios (RR). In situations where ordinal categorical predictors were assessed (number of years since completion of training and average number of cystectomies performed yearly) the Mantel-Haenszel extension test for trend was used, with mid-range values for weights. All tests were two-sided, with $p$-values 0.05 or less considered statistically significant.

\section{Results}

\section{Demographics}

Of the 34 Canadian SUO members solicited to participate in this survey, 27 (79\%) completed the survey. Almost all respondents completed a urologic oncology fellowship (24; $89 \%)$. Eighteen (70\%) participants had been in practice for at least 6 years and $21(78 \%)$ perform greater than 10 radical cystectomies each year (Table 1). Among all 688 SUO members, 86 respondents met inclusion criteria after excluding residents, fellows and staff who responded, but did not perform radical cystectomy. Use of anti-hemorrhagic agents and techniques were consistent between Canadian and all respondents, therefore, data were analyzed together to determine associations (Table 1).

\section{Blood loss and transfusion}

Most urologists $(14 ; 52 \%)$ estimated that more than $20 \%$ of radical cystectomy patients receive blood transfusion and 1 $(4 \%)$ surgeon reported that transfusion is given to more than $50 \%$ of patients (Table 2). Sixteen (59\%) urologists transfused patients at a specified threshold hemoglobin concentration. Among those who used transfusion thresholds, most (14; $88 \%$ ) used a threshold of $80 \mathrm{~g} / \mathrm{L}$ or less in the absence of cardiovascular disease and 15 (94\%) used a threshold of $100 \mathrm{~g} / \mathrm{L}$ or less in the presence of cardiovascular disease.

\section{Topical agents}

Topical hemostatic agents are frequently used by urologists (Table 3). Twenty-four (92\%) reported using oxidized cellulose polymer (Surgicel), 11 (42\%) using absorbable gelatin sponge (Gelfoam), 9 (35\%) using gelatin and thrombin matrix (Floseal), and 3 (12\%) using thrombin and fibrinogen (Tisseel). Surgeons who perform more than 40 radical 


\begin{tabular}{|c|c|c|}
\hline & Canadian & All \\
\hline Total urologists & 27 & 86 \\
\hline \multicolumn{3}{|l|}{ Practice location } \\
\hline Canada & $27(100 \%)$ & $27(32 \%)$ \\
\hline USA & $0(0 \%)$ & $52(61 \%)$ \\
\hline Europe & $0(0 \%)$ & $2(2 \%)$ \\
\hline Central/South America & $0(0 \%)$ & $2(2 \%)$ \\
\hline Australia & $0(0 \%)$ & $1(1 \%)$ \\
\hline Other & $0(0 \%)$ & $1(1 \%)$ \\
\hline \multicolumn{3}{|c|}{ Years since training completion } \\
\hline Less than 1 year & $2(7 \%)$ & $3(4 \%)$ \\
\hline $1-5$ years & $6(22 \%)$ & $25(29 \%)$ \\
\hline $6-10$ years & $10(37 \%)$ & $23(27 \%)$ \\
\hline $11-15$ years & $3(11 \%)$ & $11(13 \%)$ \\
\hline $16-20$ years & $5(19 \%)$ & $12(14 \%)$ \\
\hline Greater than 20 years & $1(4 \%)$ & $11(13 \%)$ \\
\hline \multicolumn{3}{|l|}{ Post-residency fellowship } \\
\hline MIS & $3(13 \%)$ & $8(11 \%)$ \\
\hline Oncology & $23(100 \%)$ & $70(97 \%)$ \\
\hline Other & $0(0 \%)$ & $2(3 \%)$ \\
\hline \multicolumn{3}{|c|}{ Location of last training (residency/fellowship) } \\
\hline Canada & $9(33 \%)$ & $11(13 \%)$ \\
\hline USA & $18(66 \%)$ & $73(76 \%)$ \\
\hline Europe & $0(0 \%)$ & $1(1 \%)$ \\
\hline \multicolumn{3}{|c|}{ No. radical cystectomies each year } \\
\hline $1-5$ & $3(11 \%)$ & $7(8 \%)$ \\
\hline $6-10$ & $3(11 \%)$ & $10(12 \%)$ \\
\hline $11-15$ & $4(15 \%)$ & $12(14 \%)$ \\
\hline $16-20$ & $6(22 \%)$ & $13(15 \%)$ \\
\hline $21-30$ & $7(26 \%)$ & $21(25 \%)$ \\
\hline $31-40$ & $2(7 \%)$ & $9(11 \%)$ \\
\hline $41-50$ & $1(4 \%)$ & $4(5 \%)$ \\
\hline$>50$ & $1(4 \%)$ & $9(11 \%)$ \\
\hline
\end{tabular}

cystectomies per year were less likely to use topical agents for hemostatic control (RR 0.61, 95\% Cl: 0.38-0.99) and surgeons who have been in practice longer were less likely to use topical agents (Table 4).

\section{Systemic agents}

A small number of surgeons routinely administered systemic hemostatic agents, with only $1(4 \%)$ ever using factor VII, 3 (12\%) ever using desmopressin, 3 (12\%) ever using tranexamic acid, and none ever using aminocaproic acid (Table 3). Various reasons were provided to explain why systemic drugs were not used (Table 5). No notable associations were identified between surgeon characteristics and use of systemic hemostatic agents (Table 4).

\begin{tabular}{cc}
\hline Table 2. Transfusion triggers of respondents \\
\hline Estimated proportion of patients requiring transfusion \\
$0 \%$ & $0(0 \%)$ \\
$1-10 \%$ & $6(22 \%)$ \\
$11-20 \%$ & $7(26 \%)$ \\
$21-30 \%$ & $6(22 \%)$ \\
$31-50 \%$ & $7(26 \%)$ \\
$>50 \%$ & $1(4 \%)$ \\
Transfusion at a specific hemoglobin concentration? \\
Yes & $16(59 \%)$ \\
$\mathrm{No}$ & $11(41 \%)$ \\
Transfusion triggers WITHOUT cardiovascular disease \\
$70 \mathrm{~g} / \mathrm{L}$ & $5(31 \%)$ \\
$80 \mathrm{~g} / \mathrm{L}$ & $9(56 \%)$ \\
$90 \mathrm{~g} / \mathrm{L}$ & $0(0 \%)$ \\
$100 \mathrm{~g} / \mathrm{L}$ & $0(0 \%)$ \\
Other (e.g., Ht) & $2(13 \%)$ \\
Transfusion triggers WITH cardiovascular disease \\
$70 \mathrm{~g} / \mathrm{L}$ & $1(6 \%)$ \\
$80 \mathrm{~g} / \mathrm{L}$ & $4(25 \%)$ \\
$90 \mathrm{~g} / \mathrm{L}$ & $2(13 \%)$ \\
$100 \mathrm{~g} / \mathrm{L}$ & $8(50 \%)$ \\
Other (e.g., Ht) & $1(6 \%)$ \\
\hline $\mathrm{Ht}$ hematocrit. &
\end{tabular}

\section{Procedural techniques}

A moderate number of surgeons reported using procedural hemostatic techniques, such as CellSaver $(8 ; 31 \%)$, autologous blood banking $(4 ; 15 \%)$, or acute normovolemic hemodilution (10; 26\%) (Table 3). However, analysis did reveal an association between the number of years in practice and use of procedural techniques for hemostasis. Surgeons in practice longer were more likely to use procedural hemostatic techniques compared to surgeons early in their practice (RR 3.25, 95\% Cl: 1.50-7.05) (Table 4).

\section{Discussion}

Radical cystectomy is often associated with significant blood loss and subsequent allogenic blood transfusion. ${ }^{4}$ Intra-operative blood loss is associated with morbidity and mortality. ${ }^{8}$ Blood products used in surgery increase the transmission risk of hepatitis, human immunodeficiency virus, parvovirus B19 and human T-lymphotropic virus type I and II. ${ }^{11}$ Transfusion also increases the risk of allo-immunization, hemolytic and allergic reactions and transfusion-related acute lung injury. ${ }^{11}$ Blood transfusions represent significant financial burden to the healthcare system and methods to reduce its use are warranted. The purpose of this survey was to evaluate the opinions and practice patterns regard- 
Table 3. Estimated proportion of cases when topical, systemic and procedural hemostatic methods were used Topical hemostatic agents

\begin{tabular}{|c|c|c|c|c|c|}
\hline & $\begin{array}{l}\text { Oxidized cellulose } \\
\text { polymer (Surgicel) }\end{array}$ & $\begin{array}{l}\text { Absorbable gelatin } \\
\text { sponge (Gelfoam) }\end{array}$ & $\begin{array}{l}\text { Gelatin and thrombin } \\
\text { matrix (Floseal) }\end{array}$ & $\begin{array}{c}\text { Thrombin and } \\
\text { fibrinogen (Tisseel) }\end{array}$ & Other \\
\hline $0 \%$ & $2(8 \%)$ & $15(58 \%)$ & $17(65 \%)$ & $23(88 \%)$ & $24(92 \%)$ \\
\hline $1-4 \%$ & $6(23 \%)$ & $6(23 \%)$ & $7(27 \%)$ & $1(4 \%)$ & $0(0 \%)$ \\
\hline $5-10 \%$ & $7(27 \%)$ & $3(12 \%)$ & $0(0 \%)$ & $1(4 \%)$ & $1(4 \%)$ \\
\hline $11-20 \%$ & $4(15 \%)$ & $1(4 \%)$ & $2(8 \%)$ & $0(0 \%)$ & $0(0 \%)$ \\
\hline $21-50 \%$ & 2 (8\%) & $0(0 \%)$ & $0(0 \%)$ & $0(0 \%)$ & $1(4 \%)$ \\
\hline$>50 \%$ & $5(19 \%)$ & $1(4 \%)$ & $0(0 \%)$ & $1(4 \%)$ & $0(0 \%)$ \\
\hline
\end{tabular}

Systemic hemostatic agents

\begin{tabular}{|c|c|c|c|c|c|}
\hline & Factor VII (Novoseven) & $\begin{array}{c}\text { Aminocaproic acid } \\
\text { (Amicar) }\end{array}$ & $\begin{array}{c}\text { Tranexamic acid } \\
\text { (Cyklokapron) }\end{array}$ & Desmopressin (DDVAP) & Other \\
\hline $0 \%$ & $25(96 \%)$ & $26(100 \%)$ & $23(88 \%)$ & $23(88 \%)$ & $26(100 \%)$ \\
\hline $1-4 \%$ & $1(4 \%)$ & $0(0 \%)$ & $2(8 \%)$ & $3(12 \%)$ & $0(0 \%)$ \\
\hline $5-10 \%$ & $0(0 \%)$ & $0(0 \%)$ & $0(0 \%)$ & $0(0 \%)$ & $0(0 \%)$ \\
\hline $11-20 \%$ & $0(0 \%)$ & $0(0 \%)$ & $0(0 \%)$ & $0(0 \%)$ & $0(0 \%)$ \\
\hline $21-50 \%$ & $0(0 \%)$ & $0(0 \%)$ & $1(4 \%)$ & $0(0 \%)$ & $0(0 \%)$ \\
\hline$>50 \%$ & $0(0 \%)$ & $0(0 \%)$ & $0(0 \%)$ & $0(0 \%)$ & $0(0 \%)$ \\
\hline
\end{tabular}

Procedural techniques

\begin{tabular}{lccc} 
& $\begin{array}{c}\text { Autologous blood } \\
\text { recovery (CellSaver) }\end{array}$ & $\begin{array}{c}\text { Autologous blood } \\
\text { banking }\end{array}$ & $\begin{array}{c}\text { Acute normovolemic } \\
\text { hemodilution }\end{array}$ \\
\cline { 2 - 4 } $0 \%$ & $18(69 \%)$ & $22(85 \%)$ & $16(62 \%)$ \\
$1-4 \%$ & $4(15 \%)$ & $3(12 \%)$ & $3(12 \%)$ \\
$5-10 \%$ & $1(4 \%)$ & $1(4 \%)$ & $2(8 \%)$ \\
$11-20 \%$ & $0(0 \%)$ & $0(0 \%)$ & $1(4 \%)$ \\
$21-50 \%$ & $0(0 \%)$ & $0(0 \%)$ & $3(12 \%)$ \\
$>50 \%$ & $3(12 \%)$ & $0(0 \%)$ & $1(4 \%)$
\end{tabular}

Oxidized cellulose polymer: Surgicel, Ethicon Inc., Somerville, NJ; Absorbable gelatin sponge: Gelfoam, Pfizer, New York, NY; Gelatin and thrombin matrix: Floseal, Baxter Healthcare Corporation, Hayward, CA; Thrombin and fibrinogen: Tisseel, Baxter Healthcare Corporation, Hayward, CA; Factor VII: Novoseven, Novo Nordisk Inc., Princeton, NJ; Aminocaproic acid: Amicar, Xanodyne Pharmaceuticals, Inc., Newport, KY; Tranexamic acid: Cyclokapron, Pfizer, New York, NY; Desmopressin: DDAVP, Ferring Pharmaceuticals Ltd., West Drayton, United Kingdom; Autologous blood recovery: CellSaver, Haemonetics, US.

ing perioperative hemostasis among urologists who perform radical cystectomy.

More than half of surgeons reported that they transfuse at a specific hemoglobin concentration (trigger), and many adjust this trigger depending on the cardiovascular status of the patient. Evidence supporting perioperative transfusion triggers is weak. ${ }^{12}$ However, a systematic review by the International Consensus Conference on Transfusion Outcomes Group reported that a hemoglobin concentration $<79 \mathrm{~g} / \mathrm{L}$ may be an appropriate trigger for transfusion, and a hemoglobin concentration $>100 \mathrm{~g} / \mathrm{L}$ likely does not necessitate transfusion. ${ }^{12}$ Therefore, it seems that current urology practice is consistent with the limited available evidence and recommendations for transfusion triggers.

Surgeons frequently reported using topical hemostatic agents, with $88 \%$ using at least one agent. These agents support or induce localized clot formation and have been shown to be effective in animal trials. ${ }^{13}$ Beneficial effects have also been suggested from human cohort studies; however, the evidence supporting routine use is lacking and a quantitative benefit (e.g., reducing risk of blood transfusion) has yet to be defined. ${ }^{13}$ Urologists who performed more than 40 radical cystectomies yearly were less likely to report using topical hemostatic agents. The reason for this association is unknown, but it may be attributed to individual surgical skill and familiarity with the procedure resulting in reduced blood loss, and therefore, decreased reliance on topical agents. Conversely, these surgeons may believe topical agents are not effective and resort to alternate methods of hemostasis.

Systemic agents, such as lysine analogues (tranexamic acid and aminocaproic acid), desmopressin and recombinant activated Factor VII are almost never used during radical cystectomy. Lysine analogues prevent fibrinolysis by competitively inhibiting the conversion of plasminogen to plasmin; desmopressin stimulates the release of von Willebrand factor, and exogenous Factor VII promotes coagulation in the presence of tissue factor. ${ }^{9} \mathrm{~A}$ meta-analysis of over 252 randomized controlled trials of lysine analogues, 173 of which were cardiac, and 53 orthopedic, has illustrated a clear clinical benefit in surgical blood loss. ${ }^{9}$ In addition, a recent randomized controlled trial of tranexamic acid during radical prostatectomy revealed a $38 \%$ relative reduction in blood transfusion with 
Table 4. Associations between surgeon characteristics and use of topical hemostatic agents, systemic hemostatic agents and procedural techniques

\begin{tabular}{|c|c|c|c|c|c|c|c|}
\hline & \multirow{2}{*}{ Characteristic } & \multicolumn{2}{|c|}{ Topical } & \multicolumn{2}{|c|}{ Systemic } & \multicolumn{2}{|c|}{ Procedural } \\
\hline & & RR & $95 \% \mathrm{Cl}$ & RR & $95 \% \mathrm{Cl}$ & RR & $95 \% \mathrm{Cl}$ \\
\hline \multicolumn{8}{|c|}{ Current practice location } \\
\hline USA & (ref) & 1.00 & N/A & 1.00 & N/A & 1.00 & $\mathrm{~N} / \mathrm{A}$ \\
\hline Canada & & 1.11 & $0.98-1.27$ & 2.45 & $0.72-8.36$ & 1.36 & $0.83-2.24$ \\
\hline \multicolumn{8}{|c|}{ Number of years since training } \\
\hline$<5$ years & (ref) & $1.00 *$ & N/A & 1.00 & N/A & $1.00 * *$ & $\mathrm{~N} / \mathrm{A}$ \\
\hline $6-10$ years & & 0.99 & $0.88-1.11$ & 1.00 & $0.25-4.00$ & 1.82 & $0.76-4.39$ \\
\hline $11-15$ years & & 0.85 & $0.64-1.13$ & $\mathrm{~N} / \mathrm{A}$ & N/A & 1.97 & $0.76-5.12$ \\
\hline 16-20 years & & 0.78 & $0.56-1.09$ & 0.58 & $0.07-4.69$ & 3.25 & $1.50-7.05$ \\
\hline$>20$ years & & 0.75 & $0.52-1.09$ & 0.64 & $0.08-5.08$ & 3.47 & $1.61-7.47$ \\
\hline \multicolumn{8}{|c|}{ Location of last training } \\
\hline USA & (ref) & 1.00 & N/A & 1.00 & N/A & 1.00 & $\mathrm{~N} / \mathrm{A}$ \\
\hline Canada & & 1.01 & $0.81-1.26$ & 2.06 & $0.49-8.56$ & 0.94 & $0.44-2.05$ \\
\hline \multicolumn{8}{|c|}{ Number of cystectomies performed yearly } \\
\hline$<20$ & (ref) & $1.00 *$ & $\mathrm{~N} / \mathrm{A}$ & 1.00 & $\mathrm{~N} / \mathrm{A}$ & 1.00 & $\mathrm{~N} / \mathrm{A}$ \\
\hline $21-40$ & & 0.96 & $0.82-1.09$ & 0.20 & $0.03-1.50$ & 1.20 & $0.72-1.99$ \\
\hline $41+$ & & 0.61 & $0.38-0.99$ & 0.49 & $0.07-3.59$ & 0.96 & $0.45-2.07$ \\
\hline
\end{tabular}

no increase in adverse events. ${ }^{14}$ Interestingly, almost all randomized trials of systemic agents reveal a decrease in blood loss and need for transfusion. ${ }^{9}$ No trials to date have evaluated the benefits and harms of systemic agents during radical cystectomy. ${ }^{9}$ Clearly, further study is required as a significant proportion of respondents report they did not use these agents because they were unfamiliar with the benefits, side effects and methods of use (Table 4).

Use of procedural techniques was infrequent, with less than $30 \%$ of surgeons ever using acute normovolemic hemodilution, autologous blood banking or autologous blood recovery. The evidence supporting these procedural techniques is limited. Acute normovolemic hemodilution is a procedure involving preoperative removal of whole blood, where intravascular volume is maintained with reduced red cell solutions, followed by immediate reinfusion after sur- gery. ${ }^{7}$ There is evidence to suggest that it is cost-effective, safe and may reduce the need for blood transfusion in both radical prostatectomy and radical cystectomy; however, many cystectomy patients are ineligible due to preoperative anemia. ${ }^{7,15,16}$ Autologous blood banking involves blood donation prior to surgery, but is time consuming, inconvenient to the patient, and has a high discard rate. ${ }^{16,17}$ Lastly, autologous blood recovery (CellSaver) is the reinfusion of blood lost during the operation, which is collected, filtered, washed, processed and re-transfused, but is controversial among urologists due to theoretical risks of cancer dissemination. ${ }^{16,18}$ Interestingly, experienced urologists use these techniques more commonly than less experienced surgeons. The reasons for this association are unknown. Well-designed trials of procedural techniques would help determine if they should be used routinely during radical cystectomy.

\begin{tabular}{|c|c|c|c|c|}
\hline & Factor VII (Novoseven) & $\begin{array}{c}\text { Aminocaproic acid } \\
\text { (Amicar) }\end{array}$ & $\begin{array}{c}\text { Tranexamic acid } \\
\text { (Cyklokapron) }\end{array}$ & $\begin{array}{l}\text { Desmopressin } \\
\text { (DDVAP) }\end{array}$ \\
\hline Expensive & $9(36 \%)$ & $2(8 \%)$ & $2(9 \%)$ & $1(4 \%)$ \\
\hline Lack of literature evidence & $5(20 \%)$ & $8(31 \%)$ & $6(26 \%)$ & $5(22 \%)$ \\
\hline Unfamiliar with method of use & $9(36 \%)$ & $3(12 \%)$ & $7(30 \%)$ & $5(22 \%)$ \\
\hline Not needed & $9(36 \%)$ & $12(46 \%)$ & $14(61 \%)$ & $11(48 \%)$ \\
\hline Not familiar with benefits & $8(32 \%)$ & $6(23 \%)$ & $5(22 \%)$ & $8(35 \%)$ \\
\hline Not familiar with side effects & $6(24 \%)$ & $5(19 \%)$ & $4(17 \%)$ & $3(13 \%)$ \\
\hline Lack of availability & $8(32 \%)$ & $3(12 \%)$ & $3(13 \%)$ & $0(0 \%)$ \\
\hline Side effects outweigh benefits & $2(8 \%)$ & $5(19 \%)$ & $3(13 \%)$ & $0(0 \%)$ \\
\hline Other & $1(4 \%)$ & $0(0 \%)$ & $0(0 \%)$ & $2(9 \%)$ \\
\hline
\end{tabular}

Factor VII: Novoseven, Novo Nordisk Inc., Princeton, NJ; Aminocaproic acid: Amicar, Xanodyne Pharmaceuticals, Inc., Newport, KY; Tranexamic acid: Cyclokapron, Pfizer, New York, NY; Desmopressin: DDAVP, Ferring Pharmaceuticals Ltd., West Drayton, United Kingdom. 
Punjani et al.

There are several potential limitations to this study. Most respondents were from North America; therefore, the results may not reflect surgeon opinions in other geographic areas. Outside of Canada, respondent bias is possible as only 86 of 688 SUO surgeons completed the survey. However, it is impossible to determine a true response rate since the proportion of members emailed who fit the inclusion criteria (perform radical cystectomy), or who have active email addresses, is unknown. Furthermore, opinions of SUO members may not be generalizable to the greater urology community. Surgeons who perform laparoscopic/robotic cystectomy, where blood loss is less, may have been included in the survey. ${ }^{19}$ Unfortunately, this information was not collected to allow stratification. Lastly, the use of devices, such as staplers and electrosurgical vessel sealing, has been shown to reduce blood loss, but were not addressed in this survey..$^{13,20}$

\section{Conclusion}

Radical cystectomy patients commonly require blood transfusion despite meticulous surgical technique. From this survey, we have a better understanding of urologists' opinions and practices to prevent blood loss during cystectomy. Many surgeons use topical hemostatic agents, but few employ systemic agents or procedural techniques. Overall, there is limited evidence and no best-practice guideline to prevent blood loss. Future trials are necessary to better define and hopefully identify safe and effective approaches to blood conservation.

Competing interests: None declared.

This paper has been peer-reviewed.

\section{References}

1. Shabsigh A, Korets R, Vora KC, et al. Defining early morbidity of radical cystectomy for patients with bladder cancer using a standardized reporting methodology. Eur Urol 2009;55:164-74. http://dx.doi. org/10.1016/i.eururo.2008.07.031
2. Kulkarni, JN. Perioperative morbidity of radical cystectomy: A review. Indian J Urol 2011;27:226-32. http://dx.doi.org/10.4103/0970-1591.82842

3. Novara G, De Marco V, Aragona $M$, et al. Complications and mortality after radical cystectomy for bladder transitional cell cancer. J Urol 2009;182:914-21. http://dx.doi.org/10.1016/i.juro.2009.05.032

4. Lowrance, WT, Rumohr JA, Chang SS, et al. Contemporary open radical cystectomy: analysis of perioperative outcomes. J Urol 2008;179:1313-8. http://dx.doi.org/10.1016/i.juro.2007.11.084

5. Chang, SS, JA Smith Jr, N Wells, et al. Estimated blood loss and transfusion requirements of radical cystectomy. J Urol 2001;166:2151-4. http://dx.doi.org/10.1016/S0022-5347(05)65524-3

6. Gilbert WB, JA Smith Jr. Blood use strategies in urologic surgery. Urology 2000;55:461-7. http://dx.doi. org/10.1016/S0090-4295(99)00534-8

7. Terai A, Terada N, Yoshimura K, et al. Use of acute normovolemic hemodilution in patients undergoing radical prostactetomy. Urology 2004;65:5.

8. Hollenbeck BK, Miller DC, Taub D, et al. Identifying risk factors for potentially avoidable complications following radical cystectomy. J Urol 2005;174:1231-7; discussion 1237. http://dx.doi.org/10.1097/01. ju.0000173923.35338.99

9. Henry DA, Carless PA, Moxey AJ, et al. Anti-fibrinolytic use for minimising perioperative allogeneic blood transfusion. Cochrane Database Syst Rev 2011CD001886.

10. Achneck HE, Sileshi B, Jamiolkowski RM, et al. A comprehensive review of topical hemostatic agents: efficacy and recommendations for use. Ann Surg 2010;251:217-28. http://dx.doi.org/10.1097/ SLA.0b013e3181c3bcca

11. Goodnough, LT, Brecher ME, Kanter MH, et al. Transfusion medicine. First of two parts-blood transfusion. N Engl J Med 1999;340:438-47. http://dx.doi.org/10.1056/NEJM199902113400606

12. Shander $A$, Fink $A$, Javidroozi $M$, et al. Appropriateness of allogeneic red blood cell transfusion: the international consensus conference on transfusion outcomes. Transfus Med Rev 201 1;25:232-246.e53.

13. Seyednejad H, Imani M, Jamieson T, et al. Topical haemostatic agents. Br I Surg 2008;95:1 197-225. http://dx.doi.org/10.1002/bis.6357

14. Crescenti A, Borghi G, Bignami E, et al. Intraoperative use of tranexamic acid to reduce transfusion rate in patients undergoing radical retropubic prostatectomy: double blind, randomised, placebo controlled trial. BMJ 2011;343:d5701. http://dx.doi.org/10.1136/bmi.d5701

15. Takayanagi A, Masumori N, Kobayashi K, et al. Acute normovolemic hemodilution for radical retropubic prostatectomy and radical cystectomy. Urology 2008;72:401-5. http://dx.doi.org/10.1016/i.urology.2007.11.006

16. Ubee SS, Manikandan R, Gudimetla AR, et al. Cost benefits of intraoperative cell salvage in radical cystectomy. Indian J Urol 2010;26:196-9. http://dx.doi.org/10.4103/0970-1591.65386

17. Terada N, Arai Y, Matsuta Y, et al. Acute normovolemic hemodilution for radical prostatectomy: can it replace preoperative autologous blood transfusion? Int J Urol 2001;8:149-52. http://dx.doi. org/10.1046/i.1442-2042.2001.00272.x

18. Davis $M$, Sofer $M$, Gomez-Marin 0 , et al. The use of cell salvage during radical retropubic prostatectomy: does it influence cancer recurrence? BJU Int 2003;91:474-6. http://dx.doi.org/10.1046/j.1464410X.2003.04129.x

19. Abraham JB, Young JL, Box GN, et al. Comparative analysis of laparoscopic and robot-assisted radical cystectomy with ileal conduit urinary diversion. J Endourol 2007;21:1473-80. http://dx.doi.org/10.1089/ end.2007.0095

20. Chang SS, Smith JA Jr, Cookson MS. Decreasing blood loss in patients treated with radical cystectomy: a prospective randomizes trial using a new stapling device. J Urol 2003;169:951-4. http://dx.doi. org/10.1097/01.ju.0000051372.67213.ca

Correspondence: Dr. Rodney H. Breau, Department of Surgery, Division of Urology, Ottawa University Hospital, General Campus, 501 Smyth Rd, Ottawa, ON, KIH 8L6; fax: 613-739-6842; rbreau@ottawahospital.on.ca 